\title{
Radiologic and Pathologic Features of the Transmantle Sign in Focal Cortical Dysplasia: The T1 Signal Is Useful for Differentiating Subtypes
}

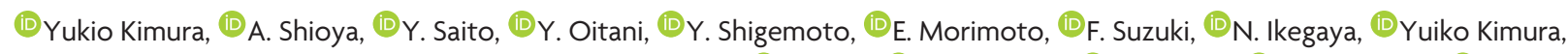

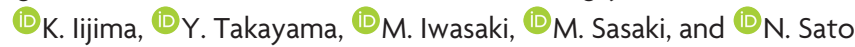

\begin{abstract}
BACKGROUND AND PURPOSE: The transmantle sign is a characteristic MR imaging finding often seen in focal cortical dysplasia type Ilb. The transmantle sign is typically hyperintense on T2WI and FLAIR and hypointense on TTWI. However, in some cases, it shows TI high signal. We evaluated the imaging and pathologic findings to identify the causes of the $T 1$ high signal in the transmantle sign.
\end{abstract}

MATERIALS AND METHODS: We retrospectively reviewed the preoperative imaging data of 141 consecutive patients with histologically proved focal cortical dysplasia. We selected 25 patients with focal cortical dysplasia with the transmantle sign and divided them into groups based on the pathologic focal cortical dysplasia subtype and $T 1$ signal of the transmantle sign. We evaluated the clinical, radiologic, and pathologic findings, including the number of balloon cells and dysmorphic neurons and the severity of gliosis or calcifications and compared them among the groups.

RESULTS: Nine of the 25 patients had a T1-high-signal transmantle sign; the other 16 patients did not. All 9 patients with a T1-high-signal transmantle sign were diagnosed as type IIb (group A). Of the 16 patients with no T1-high-signal transmantle sign, 13 were diagnosed as having type IIb (group B), and the other 3 patients, as type Ila (group C). The number of balloon cells was significantly higher in group A than in the other groups, but there were no differences regarding dysmorphic neurons, the severity of gliosis, or calcifications.

CONCLUSIONS: Approximately 6\% (9/141) of this patient series had a T1-high-signal transmantle sign, and all were type IIb. The signal may reflect a rich density of balloon cells. This finding could support the differentiation of subtypes, especially type Ilb.

ABBREVIATIONS: $\mathrm{FCD}=$ focal cortical dysplasia; ILAE = International League Against Epilepsy; $\mathrm{KB}=$ Klüver-Barrera; $\mathrm{TMS}=$ transmantle sign

$\mathbf{F}_{\mathrm{n}}$ ocal cortical dysplasia (FCD) is a localized cerebral cortical malformation frequently associated with drug-resistant focal epilepsy. ${ }^{1}$ It is critical to identify the epileptogenic focus when planning surgery. The pathologic features of FCD range from

Received February 3, 2019; accepted after revision March 27

From the Department of Radiology (Yukio K., Y. Shigemoto, E.M., F.S., N.S.), National Center Hospital, National Center of Neurology and Psychiatry, Kodaira, Tokyo, Japan; Departments of Pathology and Laboratory Medicine (A.S., Y. Saito), Child Neurology (Y.O., M.S.), and Neurosurgery (N.I., Yuiko K., K.I., Y.T., M.I.), National Center of Neurology and Psychiatry, Kodaira, Tokyo, Japan; Department of Neurology (A.S.), Mito Kyodo General Hospital, University of Tsukuba, Tsukuba, Ibaraki, Japan; Department of Pediatrics (Y.O.), Tokyo Women's Medical University Medical Center East, Tokyo, Japan; and Department of Neurosurgery (N.I.), Yokohama City University, Yokohama, Kangawa, Japan.

This work was funded by a grant from the Japan Society for the Promotion of Science (KAKENHI grant No. 17K10423).

Please address correspondence to Noriko Sato, MD, Department of Radiology, National Center of Neurology and Psychiatry, 4-1-one Ogawa-Higashi, Kodaira, Tokyo 187-8551, Japan; e-mail: snoriko@ncnp.go.jp

-- Indicates open access to non-subscribers at www.ajnr.org

三 Indicates article with supplemental on-line table.

http://dx.doi.org/10.3174/ajnr.A6067 mild cortical dyslamination to more severe forms. ${ }^{2}$ The typical MR imaging features of FCD include gray-white matter blurring, cortical thickening, white matter hypointensities on T1WI and increased signal intensity on T2WI and FLAIR images, and localized brain atrophy. ${ }^{1,3,4}$ However, it is sometimes difficult to detect such FCD features when the signal intensity is mild or the abnormality is slight.

We recently treated several patients with FCD who showed the transmantle sign (TMS), which exhibits high signal intensity not only on T2WI and FLAIR but also on T1WI. These T1-high-signal areas matched the areas of the TMS, TMS is characterized by abnormal signal intensity expanding from the deep white matter to the surface and is a distinctive MR imaging finding of type IIb FCD. ${ }^{1,5-7}$ To the best of our knowledge, only 1 study has reported such atypical signal intensity, ${ }^{8}$ and no study has examined the etiology of these signal abnormalities. We performed the present study to evaluate the signal intensity of the TMS and its correlation with pathologic findings in patients with FCD. 


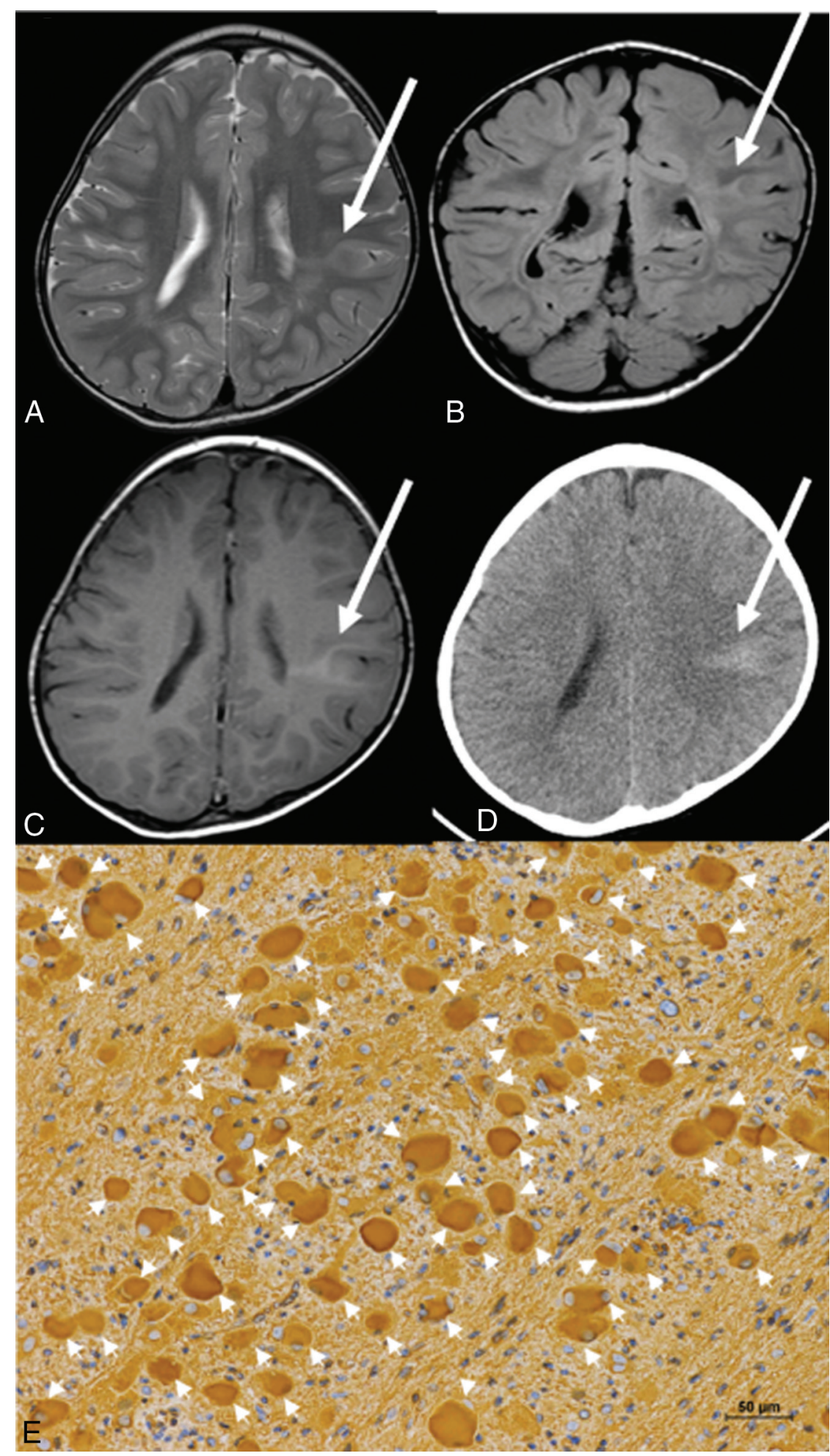

FIG 1. Case 1, in group A. Axial T2WI (A), coronal FLAIR (B), axial TTWI (C), and CT (D). T2WI and FLAIR images obtained at 23 months of age demonstrate a focal hyperintensity area from the bottom of the sulcus to the lateral ventricle, which represents the transmantle sign of FCD in the left parietal lobe (arrows, $A$ and $B$ ). The TTWI also shows hyperintensity in the same area (arrow, $C$ ). The CT image shows high density (arrow, D). E, Photomicrograph shows many balloon cells (arrowheads), stained with vimentin (magnification $\times 200$ ). Scale bars: $50 \mu \mathrm{m}$.

\section{MATERIALS AND METHODS}

\section{Patients}

We retrospectively reviewed the preoperative MR imaging data of 141 consecutive patients with histologically proved FCD who under- went an operation for refractory epilepsy between March 2008 and January 2018 at the National Center of Neurology and Psychiatry, Tokyo, Japan. All enrolled patients were diagnosed on the basis of the histologic classification system proposed by the International League Against Epilepsy (ILAE). ${ }^{9}$ There were 25 cases of FCD with TMS; 22 cases were type IIb and the other 3 cases were type IIa. The TMS was identified by the following definition: "a markedly hyperintense funnel shaped subcortical zone tapering toward the lateral ventricle was the characteristic finding on FLAIR MR imaging." ${ }^{10}$ The present retrospective study was approved by the institutional review board at the National Center of Neurology and Psychiatry Hospital, and the need for patient informed consent was waived.

We investigated clinical data including sex, age at operation, age at the onset of seizure, seizure frequency, surgery site, and postoperative seizure outcome in the 25 patients with FCD with TMS. Postoperative seizure outcome was determined at the patient's last follow-up ( $\geq 12$ months) using the ILAE criteria. ${ }^{11}$ For statistical analysis, ILAE outcomes 1 and 2 (seizure freedom or only auras since surgery) were regarded as a good outcome, and ILAE outcomes 3-6, as a poor outcome.

\section{Imaging Analysis}

All patients underwent MR imaging in a 1.5T (Magnetom Symphony; Siemens, Erlangen, Germany) or 3T (Achieva, Philips Healthcare, Best, the Netherlands, or Magnetom Verio, Siemens) system with a standard head coil. Sequences included routine structural images: axial T1WI, axial T2WI, and FLAIR images. Spin-echo T1WI was acquired with the following parameters: TR/TE/ $\mathrm{NEX}=600-613 \mathrm{~ms} / 9.4-15 \mathrm{~ms} / 1$, matrix $=201-230 \times 183-256$, FOV $=25 \mathrm{~cm}$, section thickness $=3-5 \mathrm{~mm}$. Turbo spinecho T2WI was performed with the following parameters: TR/TE/NEX $=3800-$ $5000 \mathrm{~ms} / 80-95 \mathrm{~ms} / 1-2$, matrix $=291-$ $365 \times 368-512$, FOV $=25 \mathrm{~cm}$, section thickness $=3-5 \mathrm{~mm}$. FLAIR images were acquired with the following parameters: TR/TE/NEX $=9000-12,000 \mathrm{~ms} /$ 101-120 ms/2500-2700 ms/1, matrix $=179-202 \times 256-320$, $\mathrm{FOV}=25 \mathrm{~cm}$, section thickness $=3-5 \mathrm{~mm}$. Axial and coronal

FLAIR images were obtained using the same parameters. 


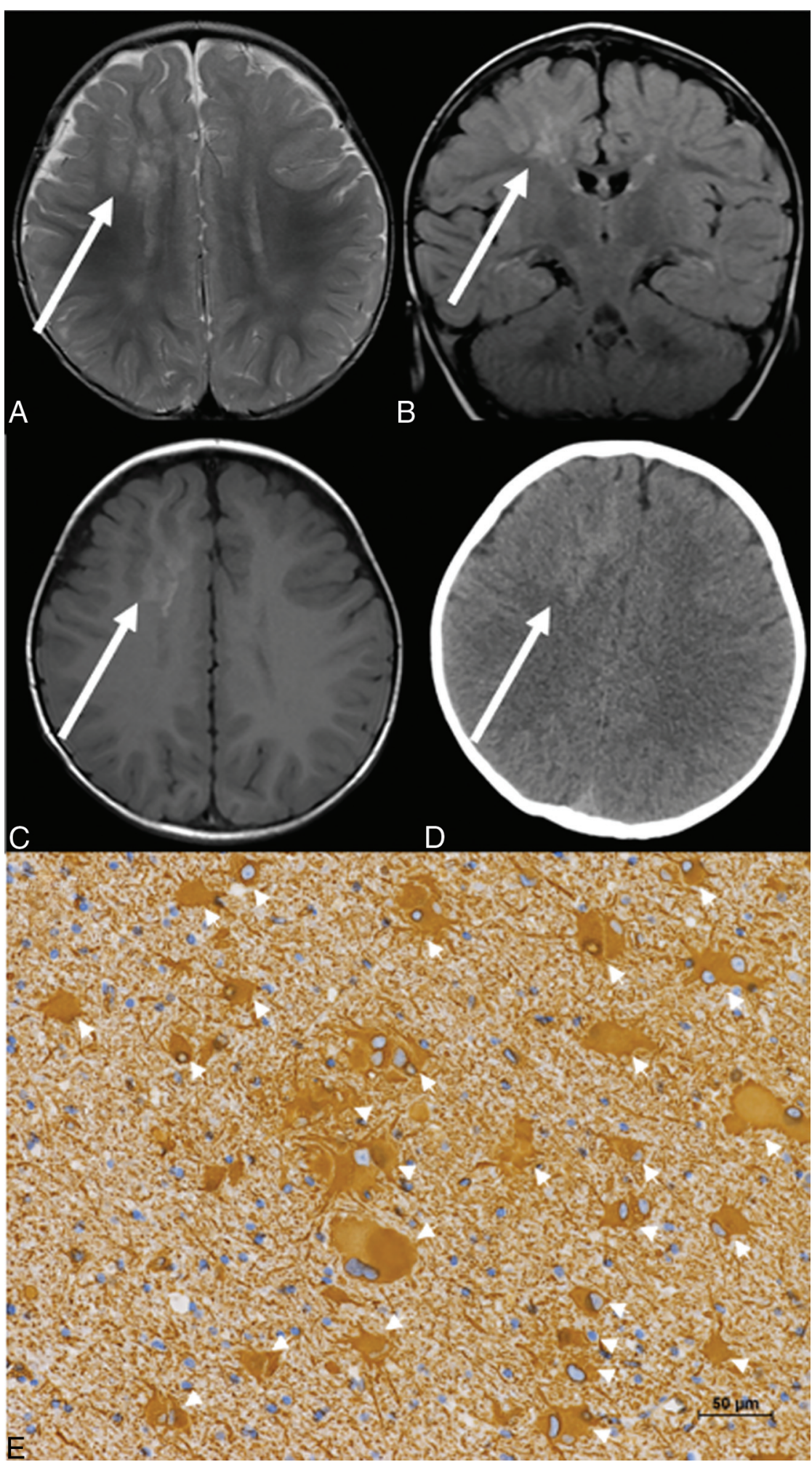

FIG 2. Case 2, in group A. Axial T2WI (A), coronal FLAIR (B), axial TIWI (C), and CT (D). T2WI and FLAIR images obtained at 13 months of age demonstrate focal hyperintensity in the white matter of the right frontal lobe, representing the TMS (arrows, $A$ and B). The TIWI also shows hyperintensity in the same area (arrow, $C$ ). The CT scan shows high density (arrow, D). E, Photomicrograph shows many balloon cells observed (arrowheads), and they are stained with vimentin (magnification $\times 200$ ). Scale bars: $50 \mu \mathrm{m}$. tensity of the TMS on T1WI, T2WI, and FLAIR images and the density on CT. The differences in evaluations were resolved by consensus.

\section{Pathologic Methods}

All specimens were diagnosed by experienced neuropathologists. For all patients, $4 \%$ paraformaldehyde-fixed paraffin-embedded tissues of the resection specimens were available. All the examined resected tissues were treated identically, grossly inspected, and measured. After representative small sections were fixed in glutaraldehyde or frozen, the remaining sections were fixed in $4 \%$ paraformaldehyde. The specimens were cut to obtain representative tissue slices perpendicular to the cortical surface. The specimens were cut into evaluable sections; 6 - $\mu \mathrm{m}$-thick serial sections were stained with antibodies to vimentin or anti-neurofilament $\mathrm{H}$ nonphosphorylated antibody (SMI-32), as well as routine hematoxylin-eosin and KlüverBarrera (KB) stains. One neuropathologist (A.S.) counted the number of balloon cells and dysmorphic neurons of each case in the FOV with the greatest number at $\times 200$ magnification in the TMS areas using vimentin and SMI-32 stains, respectively, in addition to the $\mathrm{KB}$ stain. The severity of gliosis was classified into normal, mild, moderate, and severe. The degree of calcification in the same areas was classified into absence, slight presence, and presence.

\section{Statistical Analysis}

We divided the patients into groups based on their pathologic FCD subtype and the T1 signal of the TMS. We compared the groups' ages at the onset of seizure, severity of gliosis, and number of balloon cells and dysmorphic neurons using nonparametric tests, ie, the Kruskal-Wallis or Mann-Whitney $U$ test. Regarding the postoperative seizure outcomes, we analyzed the categoric variables using the $\chi^{2}$ test. A $P$ value $<.05$ was considered significant. All statistical analyses were performed with SPSS, Version 25.0 software (IBM, Armonk, New York).
Two neuroradiologists (Yukio Kimura and Yoko Shigemoto with 14 and 10 years of experience in neuroradiology, respectively) independently evaluated all images to assess the signal in-

\section{RESULTS}

The details of the clinical demographics and radiologic and pathologic findings of the 25 patients with FCD with the TMS are 


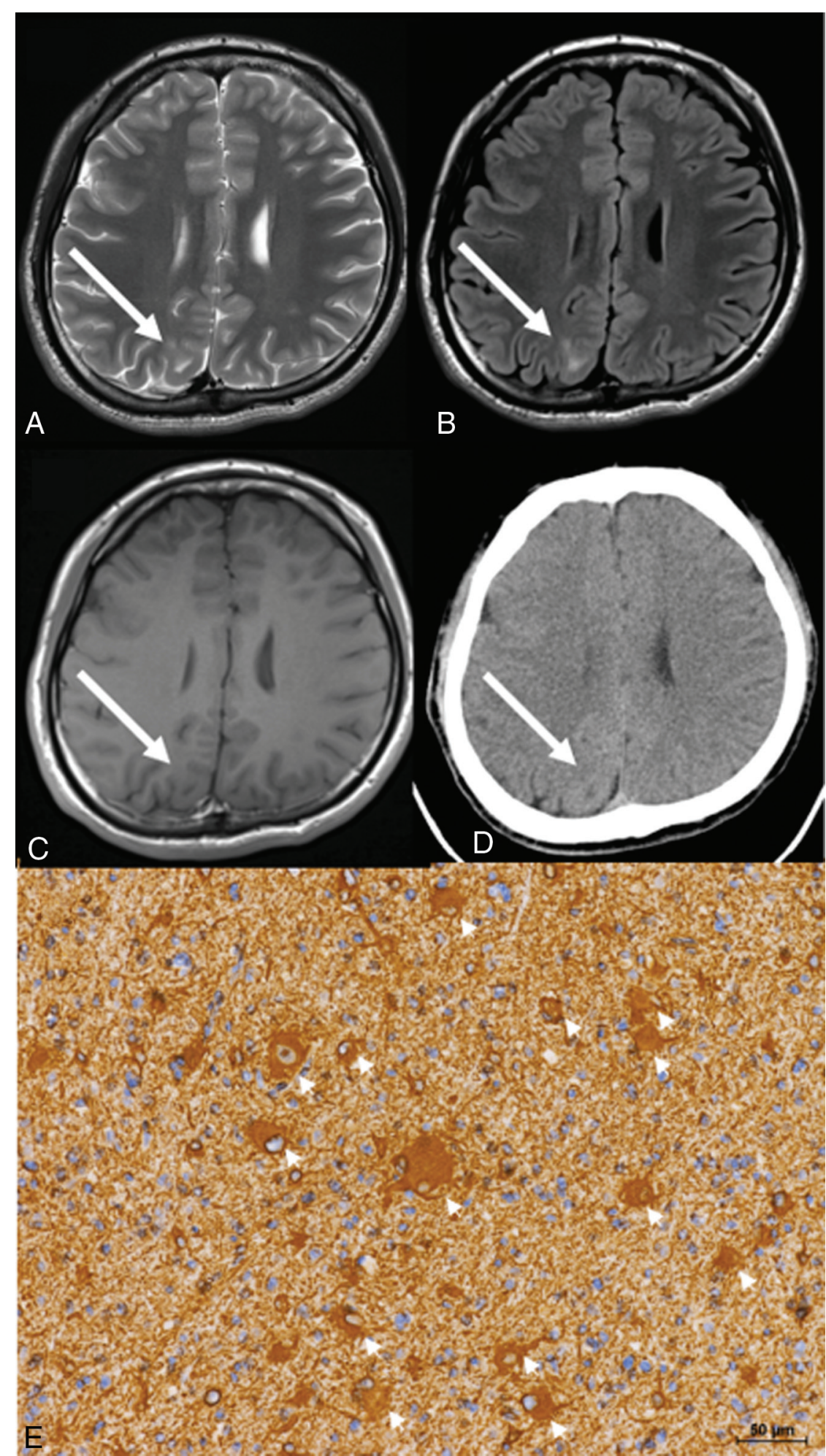

FIG 3. Case 17, in group $B$. Axial T2WI (A), axial FLAIR (B), axial TIWI (C), and CT (D). T2WI and FLAIR images obtained at 23 years of age demonstrate focal hyperintensity in the subcortical area extending to the ventricle of the right abnormal parietal gyrus, indicating the TMS (arrows, $A$ and B). TIWI shows low intensity in the same area (arrow, C). CT shows low density (arrow, D). E, Photomicrograph shows a few balloon cells (arrowheads), stained with vimentin (magnification $\times 200)$. Scale bars: $50 \mu \mathrm{m}$.

summarized in the On-line Table. We divided the patients into 3 groups based on their pathologic FCD subtype and the T1 signal of the TMS. Nine of the 25 patients had T1-high-signal
TMS, and the other 16 patients had no T1-high-signal TMS. All 9 patients with T1-high-signal TMS had been diagnosed with FCD type IIb (group A: 3 boys and 6 girls; median age, 7 years; mean age, $6.6 \pm 5.9$ years) (Figs 1 and 2). Among the 16 patients with no T1high-signal TMS, 13 patients had been diagnosed with FCD type IIb (group B: 8 males and 5 females; median age, 21 years; mean age, $21.7 \pm 14.1$ years) (Fig 3 ) and the other 3 patients had been diagnosed with FCD type IIa (group C: 3 girls; median age, 15 years; mean age, $13.3 \pm 8.6$ years). There were no patients with FCD type IIa with T1-high-signal TMS.

Among the 3 groups, there were no significant differences in the age at seizure onset $(P=.24)$ or the seizure outcomes $(P=.54)$. In group A, 8 patients had good postoperative seizure outcomes (ILAE class 1: seven patients, and class 2: one patient), and the remaining (ninth) patient had a poor outcome (ILAE class 5). In group B, 10 patients had good outcomes (ILAE class 1: nine patients, and class 2: one patient) and the other 3 patients had poor outcomes (ILAE class 5). All 3 patients in group $\mathrm{C}$ had good outcomes (ILAE class 1).

On the T2WI and FLAIR imaging, all patients showed hyperintensity in the TMS. On CT, high density was observed in the TMS in all 9 patients of group A. The hyperintense areas on T1WI matched the areas of high density on CT scans. Among the patients in groups $\mathrm{B}$ and C, though areas of slightly high density in the TMS were observed on CT in 5 patients, their densities were lower than those in the group A.

Our pathologic analysis revealed significantly more balloon cells in group A compared with group B with both $\mathrm{KB}(P=.007)$ and vimentin $(P=$ .011 ) stains (Fig 4$)$, but there was no significant difference concerning dysmorphic neurons among the 3 groups in $\mathrm{KB}(P=.69)$ and SMI-32 $(P=.52)$ stains (Fig 5). There was no significant difference in the severity of gliosis among the 3 groups $(P=.93)$. Microcalcification was observed in 4 patients in group A, but in 3 of the 4 patients, the microcalcification was imperceptible. Microcalcifications were absent in groups B and $\mathrm{C}$. 


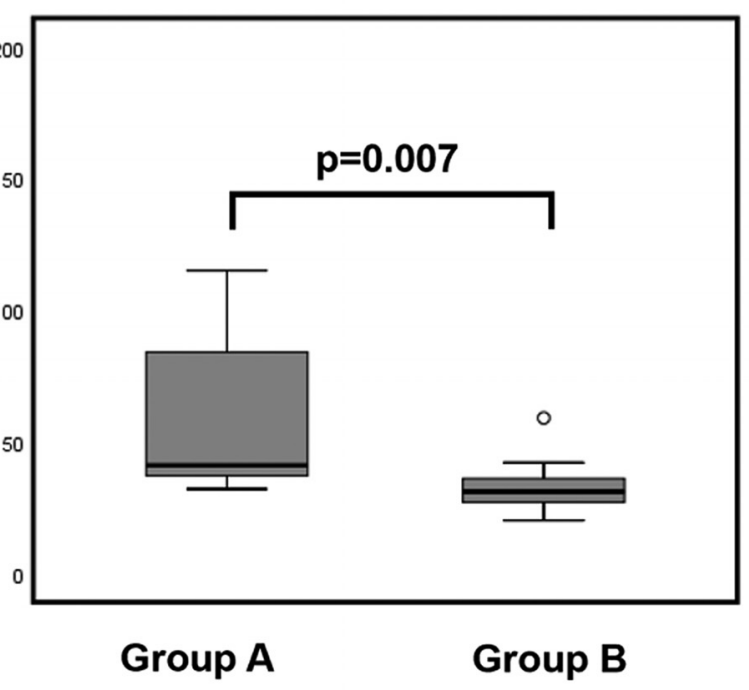

Group A
B

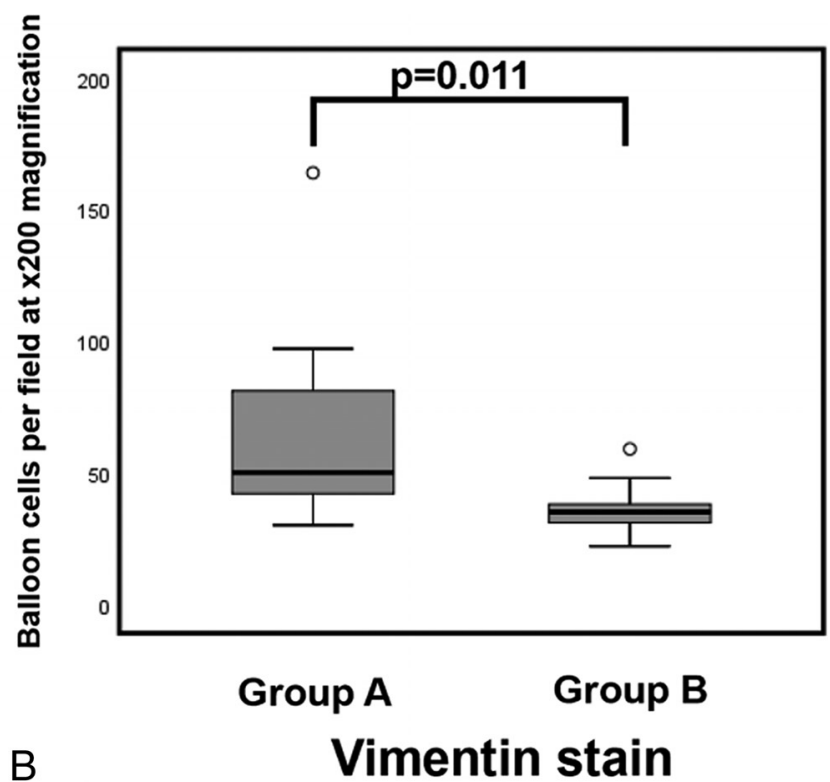

FIG 4. The greatest number of cells counted in the FOV at $\times 200$ magnification. Group differences in the number of balloon cells with $K B(A)$ and vimentin (B) stains. The boxplot shows the minimum, first quartile, median, third quartile, and maximum. Outliers are shown as small circles. The number of balloon cells is significantly higher in group A versus group B in both stains. There were no balloon cells in group C (data not shown).
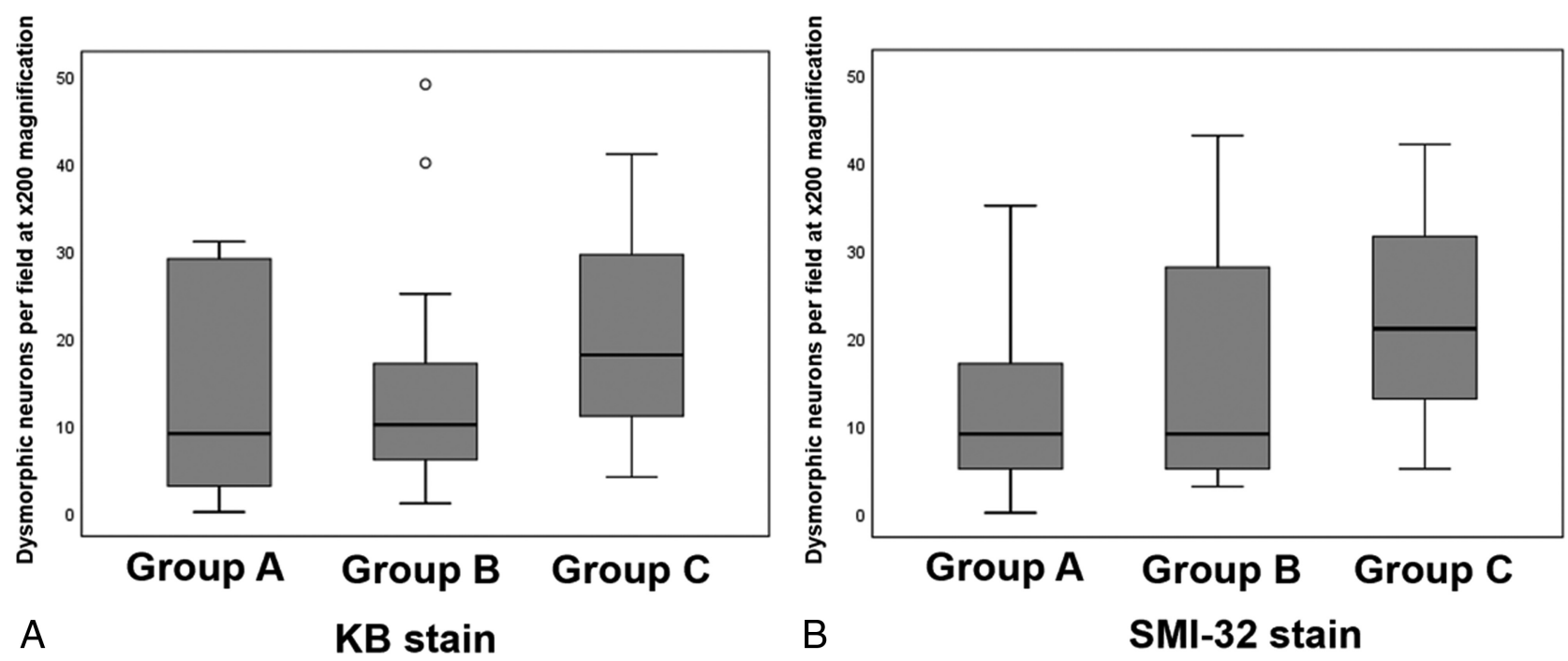

FIG 5. The greatest number of cells counted in the FOV at $\times 200$ magnification. Group differences in the number of dysmorphic neurons in KB $(A)$ and SMI-32 (B) stains. The boxplot shows the minimum, first quartile, median, third quartile, and maximum. Outliers are shown as small circles. No significant difference in the cell numbers is shown by both stains.

\section{DISCUSSION}

We reviewed the clinical, radiologic, and pathologic findings in a series of patients with T1 high signal in the TMS. To the best of our knowledge, this is the first attempt to identify the etiology of the T1 high signal of the TMS by investigating the imaging and pathologic findings. The results of our analysis demonstrated that there were significantly more balloon cells in the T1-high-signal group than the non-T1-high-signal group, but no evidence of differences regarding dysmorphic neurons, the severity of gliosis, or calcifications. We therefore speculate the following: 1) The density of the balloon cells may be associated with the T1 high signal, and 2) our findings could help diagnose the FCD subtype, more specifically FCD type IIb.

According to the current ILAE classification system, ${ }^{9}$ the pathology of FCD is classified into 3 types: Type I has isolated cor- tical dyslamination, type II has dysmorphic neurons with or without balloon cells in addition to cortical dyslamination, and type III occurs alongside another lesion (eg, hippocampal sclerosis, tumors, or vascular malformations). ${ }^{5,9}$ The histopathologic hallmark of type IIb FCD is the presence of balloon cells, which have an enlarged cell body with eosinophilic cytoplasm and are present in all layers but tend to concentrate in the upper layers and white matter. ${ }^{12,13}$ Several studies indicate that balloon cells are not epileptogenic. ${ }^{14,15}$ Although the exact role of balloon cells remains obscure, several studies have found evidence of an increase in the mechanisms leading to glutamate clearance in areas containing balloon cells, thus reducing the spread of epileptogenic activity. ${ }^{16,17}$ Balloon cells could play a protective and/or antiepileptic role. $^{12}$ 
The TMS is the main radiologic landmark of FCD type II, but it is more frequently detected in patients with type IIb than type IIa and is the only MR imaging feature that can be used to accurately identify type IIb. ${ }^{1,5-7}$ The etiology of the signal changes in the TMS is thought to be some combination of gliosis, hypomyelination or dysmyelination, neuronal heterotopia, and balloon cells, ${ }^{6,11}$ though an exact correlation has yet to be verified. The TMS is typically hyperintense on T2WI and FLAIR and hypointense on T1WI. ${ }^{18}$ However, some patients have shown T1 high signal. Our present pathologic study reveals that there are more balloon cells in the T1-high-signal group, but there are no significant between-group differences in the number of dysmorphic neurons or the severity of gliosis. Our results suggest that the density of the balloon cells may be associated with the T1 high signal. In addition, there was no T1 high signal in the other types of FCD. The T1 high signal in the TMS may thus be regarded as evidence of type IIb.

Eltze et $\mathrm{al}^{19}$ reported patients with FCD who had shown T1 hyperintensity during the first year of their lives, but it was difficult to identify them by the process of myelination. The degree of myelination may be an additional factor to evaluate the MR imaging signal intensity of FCD in infants. In our study, only 1 patient was younger than 1 year of age (case 9 in group 1 ). However, she had undergone an operation at 5 months, and we could not observe the signal changing appearances.

Compared with other FCDs without the TMS, the presence of the TMS indicated a high likelihood of a seizure-free outcome. ${ }^{20,21} \mathrm{De}-$ tecting these lesions during a preoperative examination is important for surgical decision-making and improving postoperative outcomes. $^{1,22,23}$ If the preoperative MR imaging indicates type IIb, a favorable prognosis can be expected after surgery.

Several research groups have reported the hyperintensity of FCD and cortical tubers of tuberous sclerosis on T1-weighted images with magnetization transfer contrast. ${ }^{8,24-26}$ Although Kadom et $\mathrm{al}^{8}$ did not describe the type of FCD, these T1 hyperintensities with magnetization transfer contrast may reflect the presence of balloon cells. The cortical tubers also show MR imaging findings, known as the radially oriented white matter band, that are similar to the TMS of FCD type IIb. ${ }^{27-29}$ Magnetization transfer contrast is a technique for improving image contrast in MR imaging, based on the difference in magnetic field-induced frequencies between mobile free water protons and macromolecular bound protons. ${ }^{26,30}$ Pinto Gama et $\mathrm{al}^{25}$ noted that the density of cells and calcium deposition may also play a role by causing shortening of the water T1, leading to a decrease in the effectiveness of signal suppression by magnetization transfer contrast. However, in the present study, there were few cases with sparse calcifications in the pathologic findings, and the association between high density on CT and calcifications was weak. We therefore suspect that the high density on CT was due not to calcification but rather to a high cell concentration, especially of the balloon cells themselves. In addition, even in cases without calcifications in pathologic findings, T1 high signal was observed, and we consider that calcifications were not necessarily associated with $\mathrm{T} 1 \mathrm{high}$ signal in our patients.

This study has some limitations. First, the sample size of T1high-signal FCD cases was small (9 patients). However, we were able to detect significant relationships with the balloon cell concentration. Many cases should be examined to test this result. Second, the internal structure of the balloon cell has not been clarified. Further pathologic studies are needed to validate this information.

\section{CONCLUSIONS}

Some cases of FCD type IIb have T1 high signal in the TMS. The density of balloon cells may be associated with this phenomenon, and this information would be useful for differentiating FCD subtypes and contributing to the diagnosis of FCD and its subtypes, especially type IIb.

Disclosures: Yukio Kimura—RELATED: Grant: The Japan Society for the Promotion of Science (KAKENHI grant No. 17K10423). * Money paid to the institution.

\section{REFERENCES}

1. Colombo N, Tassi L, Deleo F, et al. Focal cortical dysplasia type IIa and IIb: MRI aspects in 118 cases proven by histopathology. Neuroradiology 2012;54:1065-77 CrossRef Medline

2. Palmini A, Najm I, Avanzini G, et al. Terminology and classification of the cortical dysplasias. Neurology 2004;62(6 Suppl 3):S2-8 Medline

3. Lerner JT, Salamon N, Hauptman JS, et al. Assessment and surgical outcomes for mild type I and severe type II cortical dysplasia: a critical review and the UCLA experience. Epilepsia 2009;50:1310-35 CrossRef Medline

4. Colombo N, Salamon N, Raybaud C, et al. Imaging of malformations of cortical development. Epileptic Disord 2009;11:194-205 Medline

5. Adler S, Lorio S, Jacques TS, et al. Towards in vivo focal cortical dysplasia phenotyping using quantitative MRI. Neuroimage Clin 2017;15:95-105 CrossRef Medline

6. Mühlebner A, Coras R, Kobow K, et al. Neuropathologic measurements in focal cortical dysplasias: validation of the ILAE 2011 classification system and diagnostic implications for MRI. Acta Neuropathol 2012;123:259-72 CrossRef Medline

7. Kim DW, Kim S, Park SH, et al. Comparison of MRI features and surgical outcome among the subtypes of focal cortical dysplasia. Seizure 2012;21:789-94 CrossRef Medline

8. Kadom N, Trofimova A, Vezina GL. Utility of magnetization transfer T1 imaging in children with seizures. AJNR Am J Neuroradiol 2013;34:895-98 CrossRef Medline

9. Blümcke I, Mühlebner A. Neuropathological work-up of focal cortical dysplasias using the new ILAE consensus classification system: practical guideline article invited by the Euro-CNS Research Committee. Clin Neuropathol 2011;30:164-77 CrossRef Medline

10. Urbach H, Scheffler B, Heinrichsmeier T, et al. Focal cortical dysplasia of Taylor's balloon cell type: a clinicopathological entity with characteristic neuroimaging and histopathological features, and favorable postsurgical outcome. Epilepsia 2002;43:33-40 Medline

11. Wieser HG, Blume WT, Fish D, et al; Commission on Neurosurgery of the International League Against Epilepsy (ILAE). ILAE Commission Report: proposal for a new classification of outcome with respect to epileptic seizures following epilepsy surgery. Epilepsia 2001;42:282-86 Medline

12. Leach JL, Greiner HM, Miles L, et al. Imaging spectrum of cortical dysplasia in children. Semin Roentgenol 2014;49:99-111 CrossRef Medline

13. Abdijadid S, Mathern GW, Levine MS, et al. Basic mechanisms of epileptogenesis in pediatric cortical dysplasia. CNS Neurosci Ther 2015;21:92-103 CrossRef Medline

14. Cepeda C, André VM, Vinters HV, et al. Are cytomegalic neurons and balloon cells generators of epileptic activity in pediatric cortical dysplasia? Epilepsia 2005;46:82-88 CrossRef Medline

15. Marusic P, Najm IM, Ying Z, et al. Focal cortical dysplasias in elo- 
quent cortex: functional characteristics and correlation with MRI and histopathologic changes. Epilepsia 2002;43:27-32 Medline

16. Gonzalez-Martinez JA, Ying Z, Prayson R, et al. Glutamate clearance mechanisms in resected cortical dysplasia. J Neurosurg 2011;114: 1195-202 CrossRef Medline

17. Boonyapisit K, Najm I, Klem G, et al. Epileptogenicity of focal malformations due to abnormal cortical development: direct electrocorticographic-histopathologic correlations. Epilepsia 2003;44:69-76 Medline

18. Mellerio C, Labeyrie MA, Chassoux F, et al. Optimizing MR imaging detection of type 2 focal cortical dysplasia: best criteria for clinical practice. AJNR Am J Neuroradiol 2012;33:1932-38 CrossRef Medline

19. Eltze CM, Chong WK, Bhate S, et al. Taylor-type focal cortical dysplasia in infants: some MRI lesions almost disappear with maturation of myelination. Epilepsia 2005;46:1988-92 CrossRef Medline

20. Yao K, Mei X, Liu X, et al. Clinical characteristics, pathological features and surgical outcomes of focal cortical dysplasia (FCD) type II: correlation with pathological subtypes. Neurol Sci 2014;35: 1519-26 CrossRef Medline

21. Wang DD, Deans AE, Barkovich AJ, et al. Transmantle sign in focal cortical dysplasia: a unique radiological entity with excellent prognosis for seizure control. J Neurosurg 2013;118:337-44 CrossRef Medline

22. Berg AT, Vickrey BG, Langfitt JT, et al; Multicenter Study of Epilepsy Surgery. The multicenter study of epilepsy surgery: recruitment and selection for surgery. Epilepsia 2003;44:1425-33 Medline
23. Bien CG, Szinay M, Wagner J, et al. Characteristics and surgical outcomes of patients with refractory magnetic resonance imagingnegative epilepsies. Arch Neurol 2009;66:1491-99 CrossRef Medline

24. Rugg-Gunn FJ, Eriksson SH, Boulby PA, et al. Magnetization transfer imaging in focal epilepsy. Neurology 2003;60:1638-45 CrossRef Medline

25. Pinto Gama HP, da Rocha AJ, Braga FT, et al. Comparative analysis of MR sequences to detect structural brain lesions in tuberous sclerosis. Pediatr Radiol 2006;36:119-25 CrossRef Medline

26. Girard N, Zimmerman RA, Schnur RE, et al. Magnetization transfer in the investigation of patients with tuberous sclerosis. Neuroradiology 1997;39:523-28 CrossRef Medline

27. Kokkinos V, Kallifatidis A, Kapsalaki EZ, et al. Thin isotropic FLAIR MR images at $1.5 \mathrm{~T}$ increase the yield of focal cortical dysplasia transmantle sign detection in frontal lobe epilepsy. Epilepsy Res 2017;132:1-7 CrossRef Medline

28. Soares BP, Porter SG, Saindane AM, et al. Utility of double inversion recovery MRI in paediatric epilepsy. Br J Radiol 2016;89:20150325 CrossRef Medline

29. Yagishita A, Arai N. Cortical tubers without other stigmata of tuberous sclerosis: imaging and pathological findings. Neuroradiology 1999;41:428-32 CrossRef Medline

30. Wolff SD, Balaban RS. Magnetization transfer contrast (MTC) and tissue water proton relaxation in vivo. Magn Reson Med 1989;10: 135-44 CrossRef Medline 